\title{
Lichen striatus due to oral isotretinoin
}

\section{Liszaj pasmowaty wywołany izotretynoiną}

\author{
Munise Daye, Koray Durmaz, Pembe Oltulu \\ Department of Dermatology, Meram Faculty of Medicine, Necmettin Erbakan University, Konyi, Turkey \\ Klinika Dermatologii Wydziału Medycznego Uniwersytetu Necmettina Erbakana w Konyi, Turcja
}

Dermatol Rev/Przegl Dermatol 2019, 106, 95-98

DOI: https://doi.org/l0.51 |4/dr.2019.83448

Lichen striatus (LS) is an acquired asymptomatic linear inflammatory skin disease which was first described by Senar and Caro in 1941. It usually affects equally boys and girls during childhood and is only rarely seen in adults. The etiology of the disease is still not clear and remains obscure [1].

We would like to report a 23-year-old female patient who developed an LS lesion on her forearm while using oral isotretinoin for acne vulgaris.

A 23-year-old female patient noticed a mild pruritic rash, which had begun 3 months ago on the dorsum of her right hand and was slowly spreading in a linear fashion to her elbow in 3 months. When she presented to our department she also had nodulocystic acne and had been using oral isotretinoin (13-cis retinoic acid) $30 \mathrm{mg} / \mathrm{kg} /$ day for 7 months. There was no history of other systemic disease or medication use except oral isotretinoin. She also does not have a family history of a dermatological disease. The eruption formed erythematous, separated but linear-shaped papules (fig. 1). The patient was in good general health and her systemic physical examination was otherwise unremarkable. Her routine laboratory tests including complete blood count, glucose, liver enzymes, urea, creatinine, thyroid hormones, ferritin, vitamin $\mathrm{B}_{12}$ and hepatitis markers were normal. On histological examination by 4-mm punch biopsy material showed focal spongiosis with lymphocytic exocytosis, coarse collagen bundles in the papillary dermis and a histiocytic infiltrate seen around the vessels of the superficial plexuses (fig. 2). Clinical and histopathological features were consistent with LS. The patient did not receive any treatment regarding this condition and we decided to observe the lesion. The lesion resolved 1 month later without any treatment (fig. 3). She continued oral isotretinoin treatment for her
Liszaj pasmowaty (lichen striatus - LS) jest nabytą, asymptomatyczną chorobą zapalną skóry charakteryzującą się występowaniem zmian o układzie linijnym. Schorzenie po raz pierwszy opisali Senar i Caro w 1941 roku [1]. Choroba dotyczy głównie dzieci, z podobną częstością u obu płci. Rzadko występuje u osób dorosłych. Etiologia LS nie została w pełni poznana.

Opisujemy przypadek 23-letniej pacjentki, u której LS pojawił się na skórze przedramienia podczas leczenia trądziku pospolitego izotretynoiną.

Przedstawiamy przypadek 23-letniej pacjentki z osutką o niewielkim nasileniu, z towarzyszącym świądem. Wykwity pojawiły się 3 miesiące przed zgłoszeniem do Kliniki, początkowo na grzbietowej powierzchni ręki prawej, skąd powoli, w czasie 3 miesięcy rozprzestrzeniły się w układzie linijnym w kierunku łokcia. W czasie zgłoszenia się do Kliniki u pacjentki występował także trądzik guzkowo-torbielowaty leczony od 7 miesięcy izotretynoiną (kwasem 13-cis-retinowym) w dawce $30 \mathrm{mg} / \mathrm{kg}$ m.c./dobę. W wywiadzie nie stwierdzono żadnej innej choroby układowej. Pacjentka nie przyjmowała żadnych leków poza izotretynoiną. W wywiadzie rodzinnym nie występowały choroby dermatologiczne. Wykwity miały postać oddzielonych, rumieniowych grudek o układzie linijnym (ryc. 1). Pacjentka była w stanie ogólnym dobrym, a w badaniu przedmiotowym nie stwierdzono odchyleń od stanu prawidłowego. W podstawowych badaniach laboratoryjnych (morfologia krwi, glukoza, enzymy wątrobowe, mocznik, kreatynina, hormony tarczycowe, ferrytyna, witamina $\mathrm{B}_{12}$ i markery zapalenia wątroby) również nie wykazano nieprawidłowości. W badaniu histologicznym 4-milimetrowego wycinka pobranego metodą biopsji sztancowej stwierdzono ogniskowy obrzęk gąbczasty z egzocytozą limfocytów, grube wiązki kolagenu w war- 


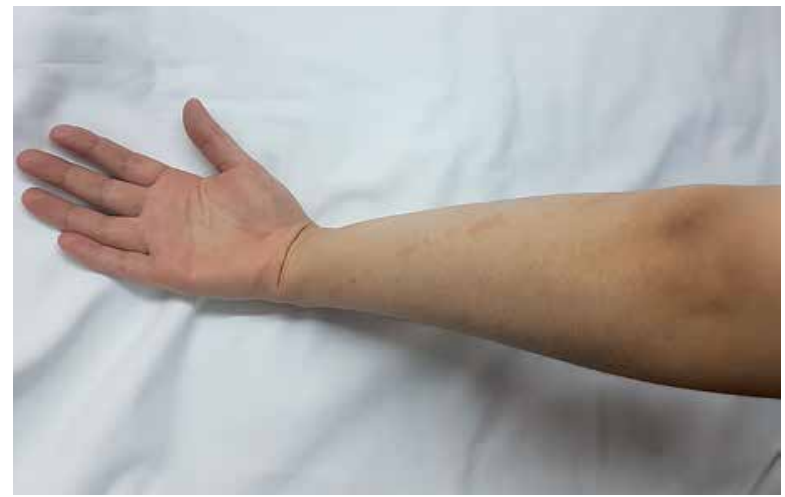

Figure I. Erythematous, separated, linear-shaped papules

Rycina I. Rumieniowe grudki o układzie linijnym

acne in that period. At a 2-month follow-up visit her oral isotretinoin treatment was stopped too.

Lichen striatus is an uncommon, acquired, benign, self-limited skin disease and is characterized by a solitary, linear band of pink, red or skin-colored, flat-topped papules in a blaschkoid distribution [2]. Lichen striatus predominantly affects children of 5-15 years of age and is usually seen on the extremities as either a continuous or an interrupted band or bands [3]. In some cases it can also be seen on different locations such as the trunk or face. It is also reported with multiple and bilateral lesions in atypical presentation [4]. Lichen striatus can be triggered by viral infections, trauma, UV exposure, BCG and hepatitis B vaccines, medications such as adalimumab and etaner-

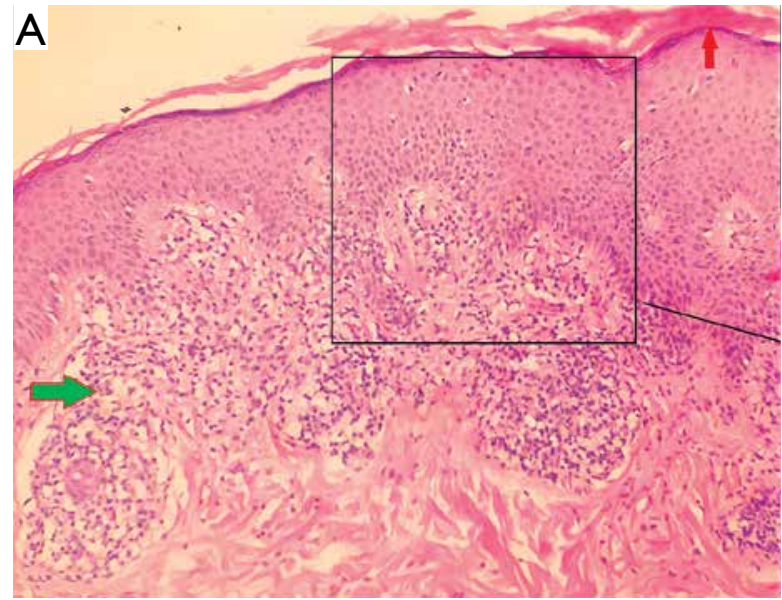

stwie brodawkowatej skóry właściwej oraz naciek z histiocytów wokół naczyń splotów powierzchownych (ryc. 2). Obraz kliniczny i histopatologiczny wskazywał na LS. U pacjentki nie podjęto leczenia, ale wyłącznie obserwację zmiany. Zmiana skórna ustąpiła w ciągu miesiąca bez stosowania terapii (ryc. 3). W tym czasie pacjentka kontynuowała przyjmowanie izotretynoiny w leczeniu trądziku. Podczas wizyty kontrolnej po 2 miesiącach zalecono odstawienie leczenia doustnego izotretynoiną.

Liszaj pasmowaty jest rzadkim, nabytym schorzeniem skóry o łagodnym i samoograniczającym przebiegu. Charakteryzuje się obecnością pojedynczych, linijnych pasm złożonych z płasko-wyniosłych grudek o zabarwieniu różowym, brązowym lub nie-

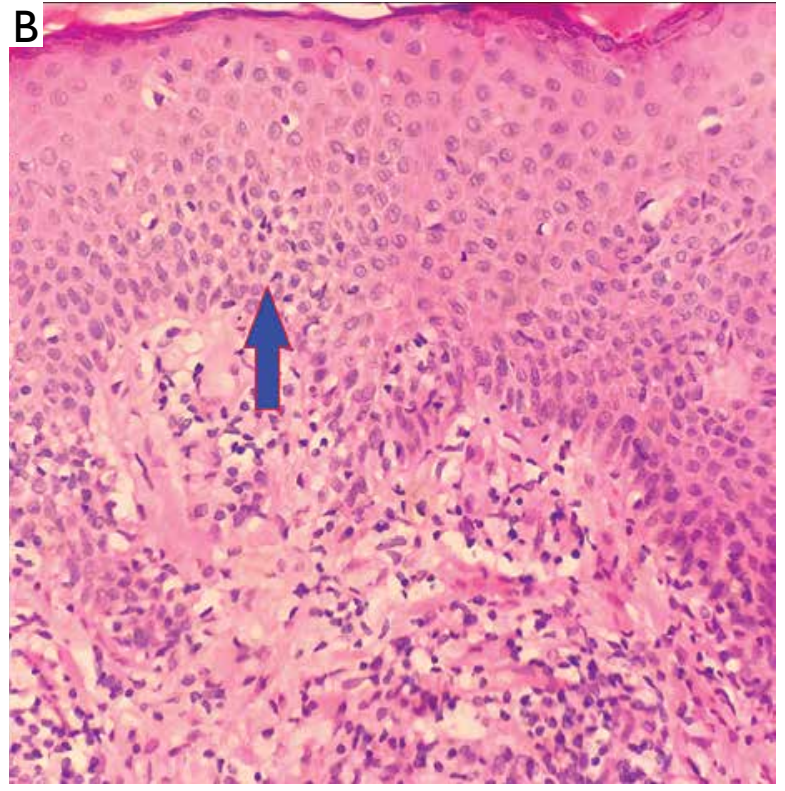

Figure 2. Focal parakeratosis (red arrow), focal spongiosis with lymphocytic exocytosis (blue arrow), slight epidermal hyperplasia, a patchy lichenoid infiltrate at the dermo-epidermal junction with histiocytes and lymphocytes (green arrow), coarse collagen bundles in the papillary dermis, a histiocytic infiltrate around the vessels of the superficial plexuses. $H+E ; A-20 \times, B-40 \times$

Rycina 2. Ogniskowa parakeratoza (czerwona strzałka), ogniskowy obrzęk gąbczasty z egzocytozą limfocytów (niebieska strzałka), nieznaczny rozrost naskórka, ogniskowy naciek liszajowy złożony z histiocytów i limfocytów wzdłuż granicy skórno-naskórkowej (zielona strzałka), grube wiązki kolagenu w warstwie brodawkowatej skóry właściwej, naciek z histiocytów wokół naczyń splotów powierzchownych. H + E; A - 20x, B - 40x 


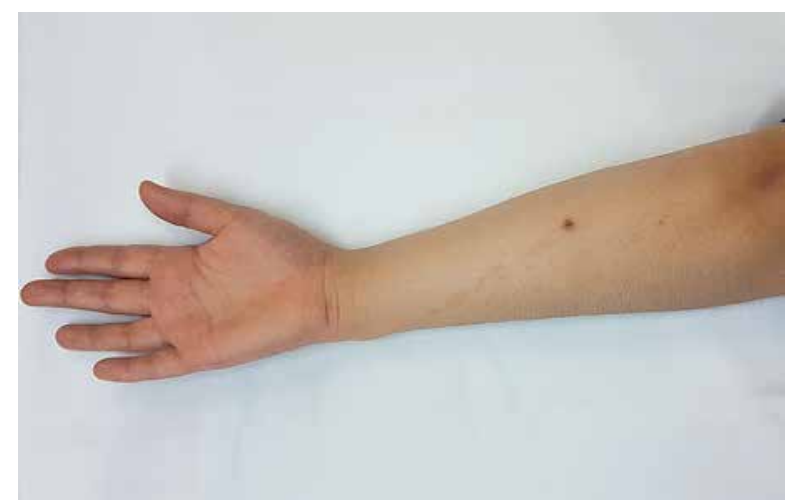

Figure 3. The lesion resolved I month later without any treatment

Rycina 3. Stan skóry po miesiącu - zmiana ustąpiła bez stosowania leczenia

cept, but the pathogenesis of it is unclear [5]. Lichen striatus and other dermatoses that follow the lines of Blaschko are thought to be caused by a somatic mutation in early embryogenesis, genetic mosaicism, or X-linked disorders due to ionization. Environmental stimuli also play a role by acting in a genetically predisposed individual. Some authors accept that LS is secondary to an autoimmune response mediated by T-cells [6]. The histopathological findings are nonspecific. They usually show a superficial perivascular lymphohistiocytic infiltrate in the dermis and lower part of the epidermis, vacuolization of the basal layer and melanin incontinence [7]. Differential diagnosis of LS includes linear psoriasis, linear porokeratosis, linear lichen planus and inflammatory linear verrucous epidermal nevus (ILVEN), linear vitiligo or nevoid hypomelanosis (the so-called hypomelanosis of Ito). Although LS can relapse and be resistant, in most cases it is self-limiting and usually regresses spontaneously within 3-12 months [3]. Our patient's lesion disappeared spontaneously in 4 months after it first occurred. In the literature, some treatment options including topical glucocorticosteroids and photodynamic therapy are reported [8]. Topical glucocorticosteroids are first-line therapy, but cutaneous side effects such as atrophy restrict use of these agents. In the cases of LS associated with itching, topical tacrolimus and oral cyclosporine have been shown to be beneficial treatment options. They can also reduce the risk of skin atrophy or dyschromia due to sequelae $[9,10]$. A reported case of LS which was unresponsive to topical glucocorticosteroid therapy regressed completely in 4 weeks with oral acitretin [2].

We have not found any association between LS and oral isotretinoin in the literature.

\section{CONFLICT OF INTEREST}

The authors declare no conflict of interest. odróżniającym się od barwy otaczającej skóry, o układzie zgodnym z liniami Blaschko [2]. Choroba dotyczy głównie dzieci, najczęściej między 5. a 15. rokiem życia. Zmiany zazwyczaj pojawiają się na skórze kończyn, gdzie przyjmują układ ciągłego lub przerywanego pasma albo kilku pasm [3]. W niektórych przypadkach wykwity występują w innych lokalizacjach, np. na tułowiu lub twarzy. Opisywano także nietypowy przebieg z obecnością mnogich i obustronnie umiejscowionych zmian [4]. Liszaj pasmowaty może być wywoływany zakażeniami wirusowymi, urazem, narażeniem na promieniowanie UV, szczepionką BCG lub przeciwko wirusowemu zapaleniu wątroby typu B albo stosowaniem niektórych leków (np. adalimumabu i etanerceptu), jednak patogeneza choroby nie jest do końca poznana [5]. Uważa się, że LS oraz inne dermatozy o przebiegu zgodnym z liniami Blaschko mogą być spowodowane mutacją somatyczną na wczesnym etapie rozwoju zarodkowego, mozaicyzmem genetycznym lub schorzeniami sprzężonymi z chromosomem X wskutek jonizacji. U osób z predyspozycją genetyczną pewną rolę odgrywają także czynniki środowiskowe. Niektórzy autorzy uważają, że LS występuje wtórnie do odpowiedzi autoimmunologicznej mediowanej przez limfocyty T [6]. Obraz histopatologiczny jest nieswoisty. Zazwyczaj w skórze właściwej i dolnej warstwie naskórka stwierdza się powierzchowny, okołonaczyniowy naciek limfohistiocytarny, wakualizację w obrębie warstwy podstawnej oraz zjawisko „nietrzymania melaniny” [7]. W diagnostyce różnicowej LS należy uwzględnić łuszczycę linijną, porokeratozę linijną, postać linijną liszaja płaskiego, zapalne linijne brodawkujące znamię naskórkowe, bielactwo linijne oraz hipomelanozę newoidalną (tzw. hipomelanozę Ito). Choć odnotowuje się przypadki nawrotów i oporności, u większości osób LS ma przebieg samoograniczający, a zmiany ustępują samoistnie w czasie 3-12 miesięcy [3]. U przedstawionej pacjentki zmiana ustąpiła samoistnie w ciągu 4 miesięcy. Opisywane w piśmiennictwie opcje terapeutyczne obejmują miejscowe leczenie 
glikokortykosteroidami oraz terapię fotodynamiczną [8]. Leczeniem pierwszego wyboru są miejscowo podawane glikokortykosteroidy, jednak potencjalne skórne działania uboczne (np. atrofia) mogą ograniczać ich stosowanie. Opisywano korzystne działanie takrolimusu stosowanego miejscowo i cyklosporyny przyjmowanej doustnie w LS z towarzyszącym świądem. Leki te mogą również zmniejszać ryzyko wystąpienia atrofii skóry lub dyschromii w następstwie terapii $[9,10]$. W jednym z opisywanych przypadków LS oporny na leczenie glikokortykosteroidami ustąpił całkowicie w ciągu 4 tygodni od wdrożenia doustnej terapii acytretyną [2].

W literaturze przedmiotu nie znaleźliśmy artykulów opisujących zależność między LS i izotretynoiną przyjmowaną doustnie.

\section{KONFLIKT INTERESÓW}

Autorzy nie zgłaszają konfliktu interesów.

\section{References}

\section{Piśmiennictwo}

1. Senear F.E., Caro M.R.: Lichen striatus. Arch Dematol Syph 1941, 43, 116-133.

2. Errichetti E., Stinco G., Trevisan G., Patrone P.: Lichen striatus associated with psoriasis vulgaris treated with oral acitretin. Indian Dermatol Online J 2014, 5, 501-503.

3. Kurokawa M., Kikuchi H., Ogata K., Setoyama M.: Bilateral lichen striatus. J Dermatol 2004, 31, 129-132.

4. Hauber K., Rose C., Bröcker E.B., Hamm H.: Lichen striatus: clinical features and follow-up in 12 patients. Eur J Dermatol 2000, 10, 536-539.

5. Lora V., Kanitakis J., Latini A., Cota C.: Lichen striatus associated with etanercept treatment of rheumatoid arthritis. J Am Acad Dermatol 2014, 70, 90-92.

6. Taieb A., El Youbi A., Grosshans E., Maleville J.: Lichen striatus: a Blaschko linear acquired inflammatory skin eruption. J Am Acad Dermatol 1991, 25, 637-642.

7. Gianotti R., Restano L., Grimalt R., Beni E., Alessi E., Caputo R.: Lichen striatus - a chameleon; an histopathological and immunohistologieal study of forty-one eases. J Cutan Pathol 1995, 22, 18-22.

8. Park J.Y., Kim Y.C.: Lichen striatus successfully treated with photodynamic therapy. Clin Exp Dermatol 2012, 37, 570-572.

9. Jo J.H., Jang H.S., Park H.J., Kim M.B., Oh C.K., Kwon K.S.: Early treatment of multiple and spreading lichen striatus with topical tacrolimus. J Am Acad Dermatol 2007, 57, 904-905.

10. Romita P., Ettorre G., Bufano T., Marzullo A., Ballini A., Dipalma B., et al.: Lichen striatus successfully treated with oral cyclosporine. Int J Immunopathol Pharmacol 2017, 30, 420-422.

Received: 10.06 .2018

Accepted: 21.01 .2019

Otrzymano: $10.06 .2018 \mathrm{r}$.

Zaakceptowano: $21.01 .2019 \mathrm{r}$. 